\title{
TUBERCULOSIS LARINGEA EN UNA GESTANTE EN UN CENTRO DE SALUD
}

\section{LARYNGEAL TUBERCULOSIS IN A PREGNANT IN A HEALTH CENTER}

\author{
Inca Ñañez-Carolina ${ }^{1,2, a}$. \\ 1. Sociedad Científica de Estudiantes de Medicina de Ica (SOCEMI). Ica,Perú \\ 2. Universidad Nacional San Luis Gonzaga de Ica \\ a. Centro de Salud Bernales - Servicio de Medicina
}

\section{RESUMEN}

La tuberculosis (TBC) es la enfermedad con mortalidad global más alta producida por un único agente infeccioso. La TBC durante la gestación es crítica incluso con tratamiento, que pueden tener reactivaciones y efectos adversos en el feto. Se describe un caso de TBC laríngea de un apaciente con embarazo gemelar a quien se le dio tratamiento según esquema del programa del Ministerio de Salud dando un excelente resultado materno-perinatal.

Palabras Claves: Tuberculosis, embarazo, epidemiología. (Fuente: DeCS BIREME).

\section{ABSTRACT}

Tuberculosis (TB) is the disease with the highest overall mortality caused by a single infectious agent. TB during pregnancy is critical even with treatment, which can have reactivations and adverse effects on the fetus. A case of laryngeal TB is described from a patient with a twin pregnancy who was treated according to the scheme of the Ministry of Health program giving an excellent maternal-perinatal result.

Key Words: Tuberculosis, pregnancy, epidemiology (Source: MeSH NLM).

\footnotetext{
Correspondencia:

Diana Carolina Inca Ñañez. Domicilio: Calle Dr. Zuñiga 153- Pisco, Ica, Perú. Número de celular: $(+511)$ : 983244070 Correo Electrónico: carolinainca16@gmail.com

Contribuciones de autoría:

DCIÑ contribuyó en la concepción, redacción, revisión y aprobación final del manuscrito.

Como citar:

Inca-Ñañez DC. Tuberculosis laríngea en una gestante en un centro de salud. Rev méd panacea. 2020; 9(1): 61-64. doi: https://doi.org/10.35563/rmp.v9i1.302
} 


\section{INTRODUCCIÓN}

La tuberculosis es una infección crónica bacteriana, causada por Mycobacterium tuberculosis o Bacilo de Koch, es caracterizada por un granuloma en el tejido afectado siendo más frecuente en los países en vías de desarrollo (1). Se caracteriza por un periodo de latencia prolongado entre la manifestación inicial y las manifestaciones clínicas en las que predomina la afección pulmonar y que afecta órganos como la laringe, con una respuesta granulomatosa con inflamación y afección de los tejidos [2]. La epidemiologia de las formas pulmonares y extra pulmonares ha cambiado desde el uso del tratamiento antituberculoso y cambios en los patrones migratorios y la pandemia del VIH. Es así como la laringe era el foco extra pulmonar más frecuentemente afectado, sin embargo en la actualidad se presenta en menos del $5 \%$ de los casos de tuberculosis extra pulmonar (1).

La edad de mayor incidencia de tuberculosis se encuentra en la adolescencia tardía y principios de la adultez, siendo la edad entre 25-34 años la de mayor incidencia en la mujer, es decir, justo en la edad reproductiva (2).

La tuberculosis laríngea constituye el $18 \%$ de las tuberculosis (TBC) de localización otorrinolaringológica, lo que se traduce en el $1,2 \%$ del total de los casos de TBC $(3,4)$, predominando en los varones con una relación 3:1. En muchos países latinoamericanos aún es posible ver algún caso de forma esporádica de esta entidad, por lo que se debe tener presente como uno de los diagnósticos diferenciales de aquellas disfonías que no ceden con tratamientos habituales (3).

La tuberculosis en la embarazada se transmite e infecta de la misma manera que en la población no embarazada, siendo la forma más común la transmisión de persona a persona mediante las gotitas de Pfluger en pacientes portadores de una TBC pulmonar o laríngea, a través de la tos o estornudo. Usualmente, después de 2-12 semanas de la infección inicial con $M$. tuberculosis, la respuesta inmune limita la multiplicación del bacilo y los test inmunológicos se vuelven positivos. Algunos bacilos pueden permanecer viables en el cuerpo por muchos años, condición conocida como infección latente (5).

En cuanto al diagnóstico de esta entidad se puede basar en análisis histológico, la tinción de Zielh Nielsen, el cultivo de secreciones y la búsqueda de ADN micobacteriano mediante la técnica de reacción en cadena de Polimerasa (PCR) (4).

Se recomienda iniciar tratamiento frente a la sospecha moderada-alta con isoniazida, rifampicina y etambutol (5). Aunque la respuesta al tratamiento antituberculoso suele ser suficiente, algunos casos descritos requieren microcirugía laríngea para corregir la disfonía.

La tuberculosis en laringe es una enfermedad poco frecuente y ha sido reportada en raras ocasiones, siendo menos común en pacientes inmunológicamente competentes lo que podría dificultar un diagnóstico temprano, que nos permita instaurar un adecuado tratamiento para un mejor pronóstico y calidad de vida de los pacientes con esta enfermedad.

\section{CASO CLÍNICO}

Gestante de 25 años de edad, referida de la provincia de Palpa, ingresa al servicio de Ginecología y Obstetricia con 32 semanas de gestación gemelar y diagnóstico de TBC laríngea, $A R O$; presentando 5 meses antes de su ingreso presento ronquera, dolor de garganta y disfonía siendo catalogada inicialmente como una bronquitis aguda y rinosinusitis. $Y$ en los últimos 2 meses progresó a odinofagia y disfagia, tos productiva, fiebre de $38^{\circ} \mathrm{C}$, astenia, disminución de peso y anorexia. Se realizó la interconsulta a otorrinolaringología, realizándose una nasofibroscopia, encontrando granuloma y lesiones leucoplásicas en epiglotis y laringe. Se realizó biopsia de la lesión cuyo análisis reporto tuberculosis laríngea. La BAAR en esputo fue positiva (100 por campo), al igual que el cultivo para $M$. tuberculosis sensible a fármacos de primera línea.

Antecedentes familiares: Hermana TBC pulmonar.

Antecedentes personales: TBC laríngea (3 mes de tratamiento)

Antecedentes Obstétricos: G2P1Ab1.

Al examen físico: presión arterial $=106 / 73 \mathrm{mmHg}$, frecuencia cardíaca $=80 \mathrm{lat} / \mathrm{min}$, frecuencia respiratoria= $20 \mathrm{resp} / \mathrm{min}, \mathrm{Pulso}=77^{\prime}$, Saturación de Oxígeno=98\%, piel y mucosas=turgente, sin pigmentaciones; llenado capilar $2^{\prime \prime} ;$ Aparato respiratorio = Tórax simétrico, $\sin$ abovedamientos ni retracciones, sonoridad conservada, no elasticidad y movilidad conservadas, sonoridad conservada de acuerdo a regiones anatómicas; Aparato cardiovascular = Se palpa choque de punta en 4to espacio intercostal izquierdo. Ruidos cardíacos normales; Abdomen $=$ grávido, con fetos activos vivos, LCF (Feto1=148 $X^{\prime}$ Feto2=150 $X^{\prime}$ ), altura uterina $32 \mathrm{~cm}$.

En la analítica se observó: $\mathrm{Hb}=8.9, \mathrm{Hto}=26.6$, Rcto de plaquetas $=240000$, Leucocitos $=12.000$ con desviación a la izquierda.

Radiografía de tórax: No se realizó por estar contraindicado en la gestación

Ecografía: útero = ocupado por dos fetos en situación longitudinal podálico izquierda y derecha. 
- Biometría fetal $\mathbf{I}=$ diámetro biparietal $(7,16 \mathrm{~cm})$, perímetro cefálico $(24,47 \mathrm{~cm})$ perímetro abdominal $(23,61$ $\mathrm{cm})$ Longitud femoral $(5.01 \mathrm{~cm})$ Peso fetal(1085 grs)

- Bienestar fetal I = Actividad cardíaca (presentes, Movimientos fetales conservados, tono fetal conservado, movimientos respiratorios conservados, líquido amniótico mide $11,03 \mathrm{~cm}$, TOTAL 10 puntos. PERFIL BIOFÍSICO NORMAL

- Anatomía fetal I = cráneo, tórax, abdomen, columna vertebral y extremidades conservadas.

- Biometría fetal II = diámetro biparietal $(7,66 \mathrm{~cm})$, perímetro cefálico $(25,27 \mathrm{~cm})$ perímetro abdominal $(23,24$ $\mathrm{cm})$ Longitud femoral $(5.08 \mathrm{~cm}$ ) Peso fetal(1097 grs)

- Bienestar fetal II = Actividad cardíaca (presentes, Movimientos fetales conservados, tono fetal conservado, movimientos respiratorios conservados, líquido amniótico mide $11,03 \mathrm{~cm}$, TOTAL 10 puntos. PERFIL BIOFÍSICO NORMAL

- Anatomía fetal II =cráneo, tórax, abdomen, columna vertebral y extremidades conservadas.

- PLACENTA Y CORDóN UMBILICAL: Localización = bicorial, biamniótica posterior, Espesor $=3,27 \mathrm{~cm}$, tortuosos con una vena y dos arterias, para cada cordón.

- CONCLUSIÓN y DIAGNÓSTICO ECOGRÁFICO: GESTACIÓN MÚLTIPLE DE 27 SEMANAS 06 DÍAS POR BIOMETRÍA FETAL.

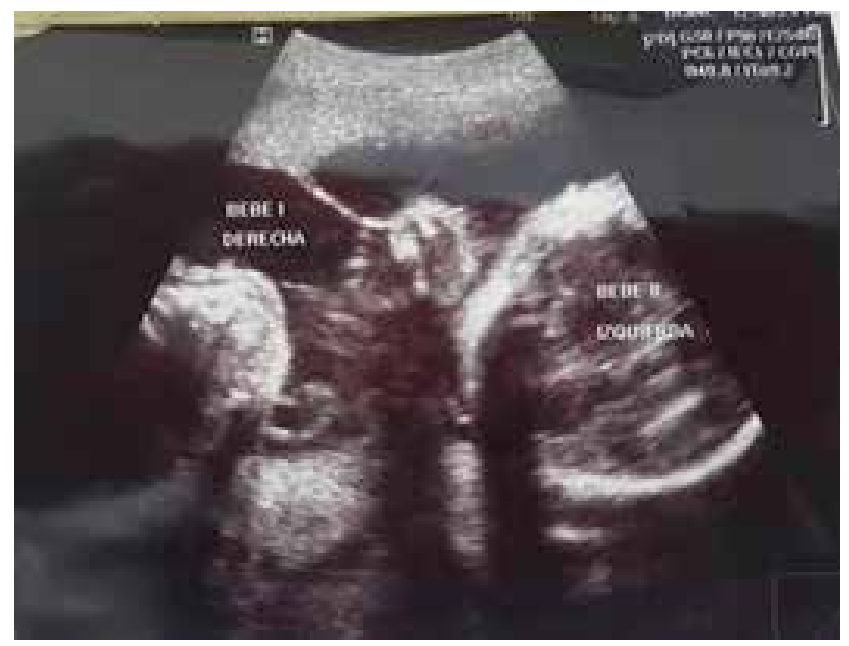

Figura 1. Ecografía muestra embarazo gemelar.

La paciente es referida al consultorio de Gineco-Obstericia y al Programa de Tuberculosis para el inicio del tratamiento.

- Isoniazida: diario o 2-3 x semana, 6-9 meses 5 mg/kg/día (hasta un máximo de 300 mg/día).
- $\quad$ Rifampicina: diario o 2-3 x semana, 2-4 meses 600 mg/día vía oral o endovenoso una vez al día. (máximo $600 \mathrm{mg} /$ día).

- $\quad$ Etambutol: diario o 2-3 x semana, 2 meses 15 $\mathrm{mg} / \mathrm{kg} /$ día. Alternativamente, puede utilizarse un tratamiento de $50 \mathrm{mg} / \mathrm{kg} /$ día dos veces por semana o 25-30 mg/kg/día tres veces por semana.

- $\quad$ Pirazinamida: diario o 3 x semana, 2 meses 15-30 $\mathrm{mg} / \mathrm{kg}$ (hasta un máximo de $2 \mathrm{~g}$ ) una vez al día.

\section{DISCUSIÓN}

La tuberculosis laríngea es la forma clínica con mayor capacidad infectante, fundamentalmente por su localización en las vías aéreas superiores y porque suele aparecer en las tuberculosis pulmonares muy evolucionadas (6).

Se considera que el principal mecanismo de producción es por extensión desde un foco pulmonar a través del contacto con el esputo cargado de bacilos. La diseminación hematógena o linfática desde un foco pulmonar como causa de la enfermedad laríngea es muy poco frecuente, en cuanto a los síntomas de presentación, el más frecuente es la disfonía, que casi siempre se acompaña de síntomas respiratorios altos (5).

El diagnóstico diferencial es el carcinoma laríngeo, por lo que es importante el estudio macroscópico y microscopio como ayuda al diagnóstico clínico [3]. Es importante tener un alto nivel de sospecha para realizar un diagnóstico precoz en la mujer gestante, ya que, si la enfermedad es diagnosticada y tratada oportuna y adecuadamente, el pronóstico materno y fetal es muy bueno. Sin embargo, Se ha visto un aumento en la incidencia de abortos y pre-eclampsia, además de un aumento en la incidencia de mortalidad perinatal (hasta seis veces mayor), prematuridad, retardo del crecimiento intrauterino y test de Apgar bajo. Estas patologías fueron más frecuentes cuando el diagnóstico fue tardío en el embarazo, el tratamiento fue irregular o incompleto y cuando las lesiones pulmonares eran avanzadas, además de la localización cuando la tuberculosis era extrapulmonar. Un estudio mostró una mortalidad neonatal del 18,7\% cuando el diagnóstico y tratamiento se realizó tardío en el embarazo (segundo y tercer trimestre), mientras que el resultado perinatal fue similar a las embarazadas no enfermas cuando el tratamiento fue realizado en el primer trimestre (5).

En cuanto al tratamiento, la pauta antituberculosa habitual ofrece resultados excelentes (5). 


\section{REFERENCIAS BIBLIOGRÁFICAS}

1. Lucas Cristóbal Reyes Meza, Nataly Matamoros Portillo, Dorysela Reyes Meza, Doris Lastenia Enamorado choa and Jorge Luis Guevara Barrientos. Facultad de Ciencias Médicas, Universidad Nacional Autónoma de Honduras, Tegucigalpa, Honduras. 2016.

2. Arrossi, S. Herrero, M.Greco, A. Ramos, S. Factores predictivos de la no adherencia al tratamiento de la tuberculosis en municipios del Área Metropolitana de Buenos Aires, Argentina. Salud colectiva, ISSN 1669-2381, Vol. 8, Nº. Extra 0, 2012, págs. 65-76.

3. Salinas, D. Moreno, D. Dennis, R. Tuberculosis pulmonar, esofágica y laríngea. Reporte de caso. Acta Med Colomb 2014; 39.

4. Jurado, L. Palacios, D. Álvarez, J. Baldión, M. Campos,
G. Diagnostico patológico y molecular de un caso de tuberculosis laríngea primaria en un médico. Departamento de Patología y Laboratorios, Fundación Santa Fe de Bogotá, Bogotá, D.C., Colombia. Biomédica 2014;34:15-20 Biomédica 2014;34:15-20.

5. Hiriart, J. Varas, Jiménez, J. Tuberculosis en el embarazo. Rev. Obstet. Ginecol.- Hosp. Santiago Oriente Dr. Luis Tisné Brousse. 2015; 1(2): 140-144.

6. Rodríguez, R. Rodríguez, A. Vidal, JL. Noguerado, A. Disfonía y Tuberculosis laríngea: presentación de dos casos y revisión bibliografía. Revista ELSEVIER, vol. 30, $N^{\circ} 8$, pag 530 - 532. Madrid - España. 2002

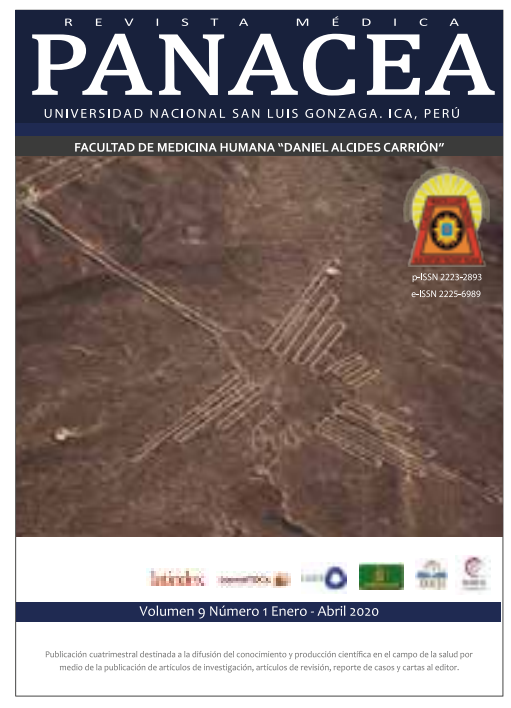

